\title{
In the Alzheimer waiting room
}

Cite as: CMAJ 2018 August 20;190:E989-90. doi: 10.1503/cmaj.180320

CMAJ Podcasts: audio reading at https://soundcloud.com/cmajpodcasts/180320-enc

resent, yet somehow deeply absent, this quiet man sitting beside me is Robert Perkins, my father. Throughout his life, many of his friends simply called him Bob, which is unfortunate because he dislikes Bob, preferring Robert or - if absolutely necessary - Rob. As children, my sister Chloe and I called him Dob ("D for Dad and rhymes with Rob"). Dad liked being called Dob; he found it endearing, often smiling when we said it. Curiously, in recent years Chloe and I have been calling him Dad, whereas our mother has started calling him Dob she has never done that before.

So here we sit in the waiting room for the memory disorders clinic. We are here for another follow-up appointment for Dad's diagnosis of probable Alzheimer disease. Mother said we should be at least a half-hour early because we wouldn't want to keep the doctor waiting. It's not like he's never kept us waiting. Mother couldn't attend today's appointment. She recently had a heart attack, from caring for Dad, I suspect. It was only a small heart attack, but it doubles the number of parents we have to worry about. Damn, this disease is so hard on families.

Today, Dad brought a dog-eared copy of Jane Eyre with him, but I doubt he will read a word. Nonetheless, this book seems to hold some special meaning. He stares at the picture of Charlotte Brontë on the cover, occasionally touching her face. I think this represents some distant, fond childhood memory. He stares at the book, and I stare at him, grappling with my own emotions.

Dad has gone from bold to old so quickly. A decade ago, he was successful, brimming with brilliance and occasional blemishes - a man with clarity of thought, no illusions and no complaints. However, about five years ago, he slowly
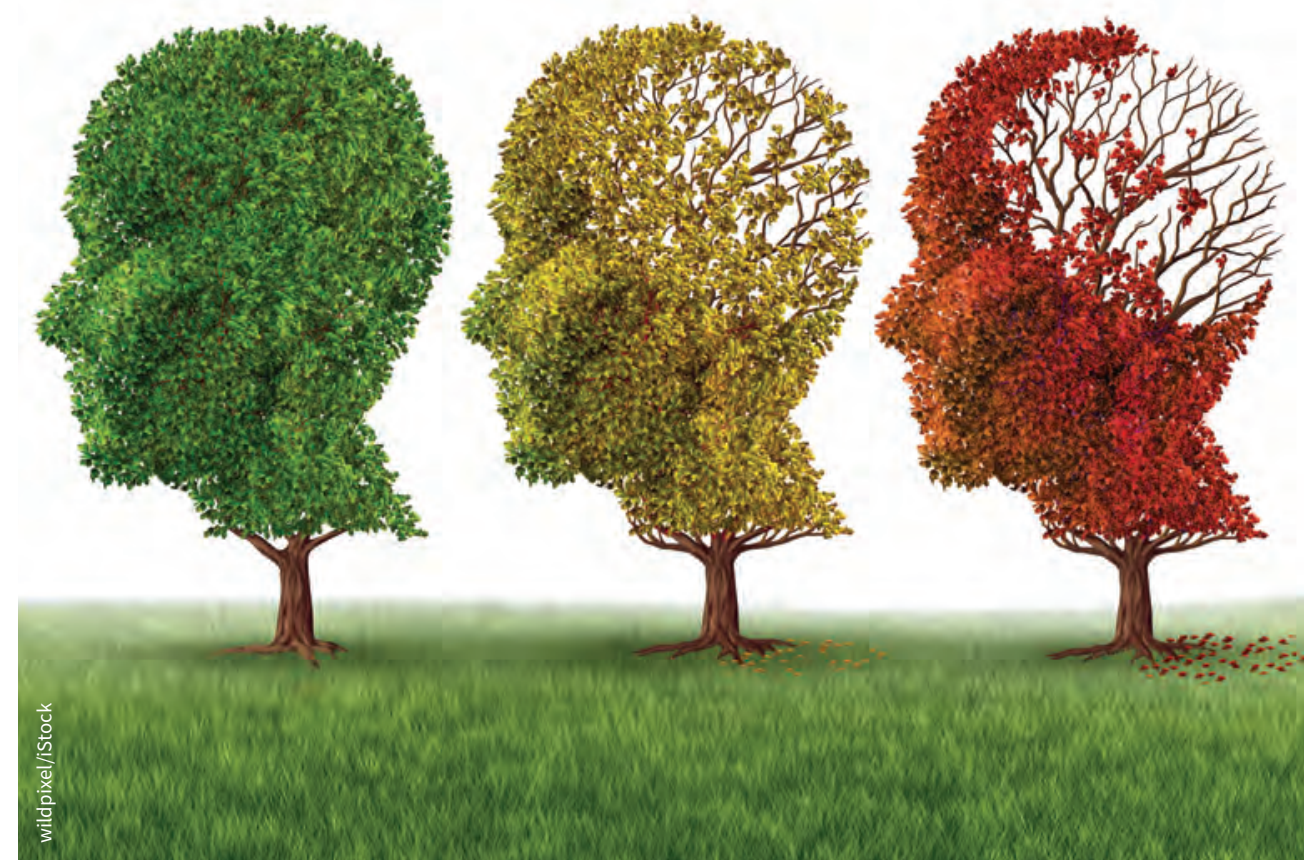

entered a forgetful state, which relentlessly deteriorated. Now, each day is just like the last, merging into an unchanging pattern and slipping into oblivion. Chloe says Dad is now in the doppelgänger phase of Alzheimer disease. This person looks like Dad, but his mind isn't there. And since your brain is what makes you, you - well, the person sitting beside me is a dad replica, not the full father of our happier years. I feel guilty that I didn't have the courage to tell him I loved him while he was still well enough to appreciate it. Maybe that is why I am here today, bringing him to this appointment, rather than my sister.

Dad somehow senses my discomfort and tries to initiate conversation: "So, how are my grandchildren? Will Teddy soon be home for Thanksgiving?"

I smile, not wanting to tell him yet again that Teddy died of leukemia more than a year ago (and that it's now March). Does he genuinely not remember? Is this some trick that his failing brain is playing to avoid the unpleasant? I pat Dad on the leg, not sure if I'm comforting him, or me. Feeling uneasy, I look around the waiting room at the other patients with families. Since many are on the same six-monthly visit cycle, I have interacted with some of them before as we wait, united by our bonds of grief and grievance.

Sitting across from me is Mrs. Pugilmos with her two daughters. As in previous clinic visits, the daughters are angry. Their 
father was an alcoholic who, 20-30 years ago, routinely beat his wife, sometimes into unconsciousness. The daughters think that these beatings contributed to, or even caused, their mother's dementia. They are angry at their father; angry that spousal abuse is an undiscussed risk factor for dementia; angry that no one seems to care about the long-term consequences of domestic violence.

And over in the corner is the no-name family: quiet, intense, suffering silently. As usual, the daughter is prepping her father for this appointment, having him draw cubes, pentagons, subtract 7 from 100 , and so on. Trying to fool the physician is simply fooling yourself. You can't negotiate with Mother Nature.

I settle back in my seat. You can't negotiate with Father Time, either. I wish I had spent more time with Dad. Now comes this avalanche of hateful emotions - fear, hopelessness, guilt, desperation - all inextricably and inexplicably combined with love. I wish I had told him I loved him, but I didn't want to confront my own emotions. Every week I would tell myself Dob is okay, l'll tell him next week. Then one week he wasn't okay.

When I was young, he played one-onone hockey with me in our driveway. I remember his handmade Christmas gifts. At the time, I thought they were silly; now I treasure them. I remember his pride when I graduated from university. I remember the father-son chat we had when I announced I was marrying Sheryl, and how he seemed to love Sheryl as much as he loved me. I remember so much that I want to say thanks for. Sure wish I had done so.

From the corner of my eye, I notice that something seems amiss. Tilting my head, I whisper, "Dad, do you have to pee?"
Looking a little embarrassed, he gives an almost imperceptible nod to the affirmative. We wander down the hall to the washrooms. Thank goodness there is a single toilet in an enclosed room with a door. I am not prepared to deal with Dad at public urinals, and those tiny metal cubicles just aren't big enough. As I encourage Dad to sit down, he retorts in annoyance: "I've been peeing standing up for as long as I can remember, and hopefully longer, since I can't remember that much," exhibiting one of those rare moments of insight mixed with humour. It takes him forever because of his prostate enlargement, but the urologist won't operate because Dad has dementia. I know he has dementia, but he does have to urinate.

We return to the waiting room, and I return to sometimes eavesdropping on, sometimes participating in, the conversations about the room.

In another corner sits Mr. Budowniczy with his wife and two sons. One of the sons is a building contractor who against their doctor's advice - recently erected a lavish new multistory home for his parents. Unfortunately, their dad got much worse when he moved into the new house, and began wandering in a bewildered state, especially at night. One son talks about the phenomenon of "sundowning," which he has read about on the Internet.

A family that I haven't seen before emerges from the examining room area, looking relieved. A younger woman speaks as they head toward the front desk: "You see Mom, your tests were not too bad. They think you're depressed, not demented. This is great news."

I'm glad someone is getting "great" news. This room needs some. The hospital waiting room: a feast and a quagmire of human disease, thought, anguish, emotion and occasional elation. I wonder if physicians ever exploit this opportunity and location to study the human condition?

Seeking an emotional reprieve, I gaze at the wall decorations. The pictures are awful, truly awful. Why am I really worried about pictures on hospital walls? Why? Because there is just too much emotion in this room - suppressed or expressed mine and everyone else's. Push those feelings down, deep. Aren't they ever going to call him for his appointment?

Finally, a young-looking resident physician comes out to the waiting room, reading a patient chart: "Perkins ... Bob Perkins." As I stand, the physician distractedly acknowledges our presence and smiles, but as a perfunctory gesture and without real warmth. My father gives that soft sigh of indignation and resignation that I have heard so often. He may have dementia, but he still hates being called Bob.

I gather my things and get ready to help Dad. It has been a very long hour, but it was spent with Dob, so I hope there are many more.

"C'mon Dob," I say. "Let's go see the doctor."

He smiles upon hearing Dob and, arising from the chair, reaches for my hand.

"There is still a lot of you in there, just not enough," I silently mutter, swallowing hard. I take his hand. He awkwardly gets to his feet, absent yet somehow clearly present.

\section{Donald F. Weaver MD PhD}

Krembil Research Institute, University Health Network, University of Toronto, Toronto, Ont.

This article has been peer reviewed.

This is a true story. Family consent was obtained. All the families in the waiting room are fictitious. 